\title{
Reflections on the Feedback Given Before and After Computer Science Programming Exercises from the Perspective of Lecturer and Student
}

\section{Reflexiones sobre la Retroalimentación antes y después de Ejercicios de Programación desde el Punto de Vista del Profesor y de los Estudiantes}

\author{
Diana Rosario Pérez Marín \\ Universidad Rey Juan Carlos, España
}

\begin{abstract}
In this paper, the question is discussed of whether it is worthwhile to devote time to providing feedback to undergraduate Computer Science students before and after they do programming exercises. A comparative study was carried out in two different years of the same course taught by the same lecturer. In the first year, feedback was only provided after each exercise was finished, while in the second year feedback was provided both before and after each exercise was finished. The results confirm that even when the number of students is higher than one hundred; it is still worthwhile to provide feedback before and after each Computer Science exercise to achieve better scores, and a drastic decrease in the drop-out rate, which was reduced to zero.

Keywords: feedback, computer science studies, continuous assessment, university studies, motivation.
\end{abstract}

Resumen. En este artículo, se discute sobre los beneficios de proporcionar retroalimentación antes y después de ejercicios de programación para estudiantes de Ingeniería Informática. Se ha realizado un estudio comparativo en dos años diferentes del mismo curso impartidos por el mismo profesor. En el primer año, la retroalimentación sólo se proporcionó después de que cada ejercicio fuese completado; mientras que en el segundo año, la retroalimentación se proporcionó tanto antes como después de que cada ejercicio fuese completado. Los resultados confirman que incluso cuando el número de estudiantes es superior a cien, sigue siendo conveniente proporcionar retroalimentación antes y después de cada ejercicio de programación para conseguir que los estudiantes obtengan mejores calificaciones, y reducir la tasa de abandono a cero.

Palabras clave: retroalimentación, informática, evaluación continua, estudios universitarios, motivación.

\section{Introduction}

Lecturers should organize their time to prepare lessons, evaluate the students' progress, provide feedback, do research and management. However, it

La correspondencia sobre este artículo debe enviarse a la autora al Despacho 2025, Edificio Ampliación Rectorado. Calle Tulipán, s/n. Departamento de Lenguajes y Sistemas Informáticos I. Escuela Técnica Superior de Ingeniería Informática. Campus de Móstoles. Universidad Rey Juan Carlos. 28933, Madrid, Spain. E-mail: diana.perez@urjc.es is usual that the most important factor for their promotions is the quality of the research.

Therefore, some lecturers may be afraid of devoting too much time to provide detailed and timely feedback to the students, because it cuts down the time they have for doing research. Furthermore, it is not clear whether providing too much feedback would be completely beneficial (Lilley, Barker and Critton, 2005), or adequate given that these students 
are adults that should be able to work on their own and solve the difficulties by themselves.

However, it was my insight that just providing feedback after the work is done was not enough. Students were not given the chance to solve the problems detected and it could prevent them to learning (Kolb, 1984).

Therefore, during two different academic years, I tried in the same course of the Computer Science degree two different levels of feedback. In both courses, the students had to do a project consisting of several exercises built one on top of the other, so that it was necessary to have finished one exercise to be able to extend it for the next exercise, and there was continuous assessment.

The main difference was that in the first year feedback was provided to the students only after each exercise, while in the second year feedback was provided to the students before and after each exercise.

The first year was during the second semester of the 2006-2007 academic year with 24 students enrolled in the course. The second year was during the second semester of the 2007-2008 academic year with 164 students enrolled in the course. In both courses, students were asked to work in pairs in several groups.

Each pair of students was studied individually to obtain information about their evolution during the course. In 2007, just the introduction of the continuous assessment with feedback after each exercise increased the average score from 5,5 up to 7,5 (in a 0 to 10 scale), and the percentage of students able to pass the course was increased up to $83 \%$. Moreover, 22 students $(92 \%)$ filled in a satisfaction questionnaire anonymously and voluntarily stating that the feedback had been really helpful for them.

On the other hand, the number of exercises had to be reduced from 4 down to $3 ; 5$ students $(4,5 \%)$ dropped out and some students complaint that the lecturer was less available to answer doubts for the next exercise, because she was only providing feedback on the last exercise completed.

In 2008, the continuous assessment was extended with feedback before the deadline of each exercise. This has made possible to keep the results in terms of students' scores with the average score of 7,5 (in the same 0-10 scale), and to increase the students' satisfaction (no complaints about the lecturer not answering doubts), the percentage of students passing the course up to $100 \%$, and to decrease the dropout rate down to 0 .

Furthermore, it was not necessary to reduce the number of practical exercises and it was possible to provide the extra feedback even with 164 students (more than 5 times the number of students in the previous year).

124 students (93\%) filled in voluntarily and anonymously a satisfaction questionnaire indicating that they prefer this type of continuous assessment with feedback before and after each exercise, and 82 students $(62 \%)$ claimed that they believed that the feedback before and after each exercise had been the key to their learning of the course.

The paper is organized as follows: Section 'Related work' provides the context of this work in the existing related research and its background; Section 'Practical experiences' describes the experiments performed; Section 'Discussion' presents the insights and reflections from her lecturer perspective after having carried out and lived both experiences, and from their students' perspective after having being asked and observed them during both years; and, finally Section 'Conclusions' ends the paper with the main ideas and possible lines of future research.

\section{Related work}

In primary and secondary education it is usual to follow the evolution of each student during the course. The number of students per class allows the implementation of a continuous evaluation, according to which, the final score of each student does not depend only on its numeric score on the final exam of the course but it takes into account all the work performed during the course. 
The higher number of students per class in the university and the opinion of some lecturers that university students should be more responsible and autonomous learners may have been the reasons why the continuous assessment has not been introduced in university until only recently.

In fact, in the last years, Spanish universities have started a deep renovation change in the context of European Studies (Benito-Capa and Cruz-Chust, 2005). One of the main changes is the way in which the lecture hours are counted. Traditionally, 1 credit covered 10 hours of face-to-face class, but with the European Space of Education, the European credit now covers 25-30 hours of both face-to-face and after class activities in which students should work on their own.

Another important change is regarding the role of the lecturers. In the European Education context, lecturers are no longer the only source of information but they have become facilitators of the students' learning.

It is important to highlight the word 'facilitators', as according to Marchesi (2004), the students are responsible for their own learning and lecturers can only be responsible for organizing the courses to foster the Meaningful Learning of their students (Ausubel, 1963), and for offering ways of assessment that foster working during the course. It is because learning requires time and effort, and it cannot be procrastinated by the previous days to a unique final exam (Zimmerman, 1990).

In some cases, it is even advisable to reduce the amount of knowledge provided during the course, because if it is too much, it could overwhelm the students and prevent them from learning (Jensen, 1998). It would also allow lecturers to provide more feedback to the students, and increase the lecturerstudents interaction (Westberg and Jason, 2001; Irons, 2007; Race and Pickford, 2010).

Students should know what they are doing right and what they are doing wrong. If the first evaluation of their work comes at the end of the course, students cannot apply the changes. Besides, the students would feel that their work is not valuable because the lecturer do not pay any attention into it, which could be a discouraging factor (Quality Assurance Agency, 2000; Brooks et al. 2006).

\section{Practical experiences}

\section{Before the 2006/2007 academic year: traditional final exam}

Operating Systems is a semester course of the second year of the Computer Science degree of the Computer Science Faculty of the Universidad Autónoma of Madrid in Spain. It has more than one hundred related and complex concepts and students usually failed to pass the course the first time that they took it.

Traditionally, the assessment has been a final exam or passing four or five practical exercises belonging to a common project. Lecturers were asked to give the students the scores before the end of the semester, with the recommendation that they should not only provide the students with their score, but that they should also indicate the main mistakes made so that students do not repeat them again in the next exercises.

Students were asked to work during all the semester, although it was not compulsory and no feedback during the course was provided.

\section{During the 2006/2007 academic year: feedback after each completed work}

In the 2006-2007 academic year, the continuous assessment was also voluntary but it was extended by providing feedback after each exercise. That way, students could solve their mistakes and avoid repeating them again in the next exercise, and lecturers could have more scores of each practical work allowing a fairest assessment based on a greater number of scores.

The number of exercises was decreased from four down to three as recommended in the related work of better focusing on the most important aspects of 
the course instead of trying to cover everything, and thus, overwhelming both the student and the lecturer with too much work.

Twenty-four students were enrolled in my group working in pairs. The agenda of the course is shown in Figure 1. As can be seen, each practical work is followed by feedback, while in the previous years there was no feedback during the course.

The result of these changes was that while in the 2004-2005 academic year, 66\% of total number of students passed the course with an average score of 6 (in a 0-10 scale); in the 2005-2006 academic year, $74 \%$ passed the course with an average score of 5,5; in the 2006-2007, in which the continuous assessment with feedback after each exercise was performed, $83 \%$ passed the course with an average of 7,5 and only the $4,5 \%$ students that dropped out the course failed it.

The results of a satisfaction questionnaire filled in anonymously and voluntarily by 22 students indicated that $96 \%$ of the students claimed that continuous assessment is the best way to assess not only concepts but also competences.

$92 \%$ of the students consider useful the feedback provided. However, some students complaint that the lecturer devoted too much time to the feedback

Figure 1. Agenda for the 2006/2007 course

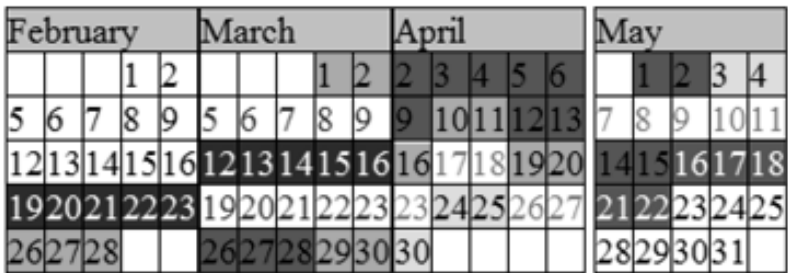

\begin{tabular}{|l|}
\hline \multicolumn{1}{|c|}{ Legend } \\
\hline First practical work \\
\hline Feedback for the first practical work \\
\hline Second practical work \\
\hline Feedback for the second practical work \\
\hline Third practical work \\
\hline Feedback for the third practical work \\
\hline Final project \\
\hline Final feedback \\
\hline Holidays \\
\hline
\end{tabular}

and she did not have time to answer doubts for the next practical exercises.

\section{During the 2007/2008 academic year: feedback before and after each completed work}

The positive results of the previous year encouraged me not only to keep the continuous assessment but to extend it with feedback before each exercise too in the 2007-2008 academic year.

164 students were enrolled in eight groups as shown in Table 1 working in pairs. The agenda of the course is shown in Figure 2. As can be seen, each practical work is not only followed by feedback about the practical work done, but also with feedback about the practical work to be done.

When the groups were below 20 students, no changes were applied with respect to the dynamic of

Table 1. Students' groups in the 2007/2008 course

\begin{tabular}{lllc}
\hline Group & Time & Room & \#students \\
\hline 3A & Monday (11:00-13:00) & Lab 6 & 7 \\
1A & Monday (15:00-17:00) & Lab 6 & 19 \\
2B & Tuesday (15:00-17:00) & Lab 6 & 21 \\
2A* & Wednesday (12:00-14:00) & Lab 6 & 27 \\
3B & Wednesday (10:00-12:00) & Lab 6 & 8 \\
2C & Wednesday (15:00-17:00) & Lab 6 & 22 \\
1B & Friday (9:00-11:00) & Lab 6 & 13 \\
1C & Friday (15:00-17:00) & Lab 6 & 14
\end{tabular}

Figure 2. Agenda for the 2007/2008 course

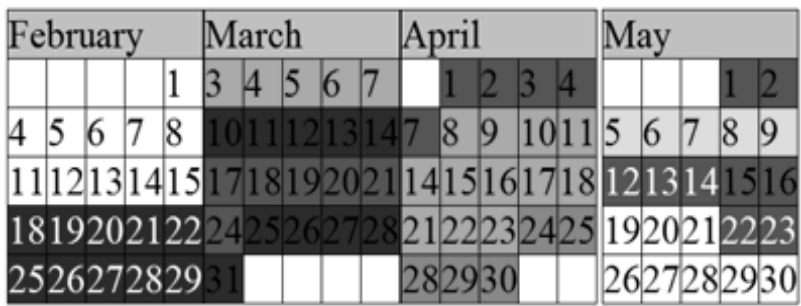

\begin{tabular}{l|}
\hline Legend \\
\hline First practical work \\
\hline Feedback before the first practical work defivery \\
\hline Second practical work \\
\hline Feedback after the first practical work and before the second practical work \\
Third practical work \\
\hline Feedback after the second practical work and before the third practical work delivery \\
\hline Third practical work delivery \\
\hline Feedback after the third practical work delivery \\
\hline Theory partial exams \\
\hline Hobdays \\
\hline
\end{tabular}


the class in the 2006/2007. However, in the groups in which there were more than 20 students, it was necessary to focus the feedback on some key aspects (e.g. difficult exercises or particularly problematic points of the code).

With the application of this continuous assessment with feedback before and after each exercise, $100 \%$ of the students passed the course with an average of 7,5.

133 students anonymously and voluntarily filled in the satisfaction questionnaire. 124 students (93\%) regarded the continuous assessment with feedback before and after each exercise positive, 111 students (83\%) claimed that the feedback provided before each exercise was useful, 115 students $(86 \%)$ claimed that the feedback after each exercise was useful, and 82 students (62\%) claimed that the feedback before and after each exercise has been key for their learning of the course.

\section{Results}

Several indicators have been used to measure the results of applying the continuous assessment with feedback before and after each practical work: the students' scores, the drop-out rate, and satisfaction questionnaires.

Regarding the students' scores, Table 2 shows the evolution in the percentage of students who have passed the course, and their average score. As can be seen, with the introduction of the feedback before and after each practical work in the 2007/2008 academic course, $100 \%$ of the students have passed the course with an average score of 7,5; and, the dropout rate has been decreased down to 0 .

Table 2. Evolution of the students' scores in Operating Systems

\begin{tabular}{lcc}
\hline Academic year & $\begin{array}{c}\text { \% students who } \\
\text { have passed }\end{array}$ & $\begin{array}{c}\text { Average score in } \\
\text { the course }\end{array}$ \\
\hline $2004 / 2005$ & 66 & 6 \\
$2005 / 2006$ & 74 & 5,5 \\
$2006 / 2007$ & 83 & 7,5 \\
$2007 / 2008$ & 100 & 7,5
\end{tabular}

The results of a satisfaction questionnaire filled in anonymously and voluntarily by 22 students of the $2006 / 2007$ course indicated that $92 \%$ of the students consider useful the feedback provided, and this result is kept in the 2007/2008 course when 93\% of the 133 students who filled in the survey indicated that they preferred having feedback before and after each practical work. Figures $3 \mathrm{a}, 3 \mathrm{~b}$ and $3 \mathrm{c}$ graphically show these percentages for the 2006/2007 and 2007/2008 courses.

Figures $4 \mathrm{a}$ and $4 \mathrm{~b}$ show the opinion of the students regarding the continuous assessment in the 2006/2007 and 2007/2008 courses. As can be seen, in both courses more than $90 \%$ of them like it.

Figures $5 \mathrm{a}$ and $5 \mathrm{~b}$ show the opinion of the students regarding if they believe that they were taking full advantage of the lessons. As can be seen, the satisfaction is much greater in the 2007/2008 course with the introduction of feedback before and after each practical work.

Finally, Figures $6 \mathrm{a}$ and $6 \mathrm{~b}$ show the opinion of the students regarding the future of the course and, how more than $70 \%$ of the students would like that this type of continuous assessment would be kept the same.

\section{Discussion}

The main goal that I pursued when I started to think about extending the continuous assessment to provide feedback before and after each practical work was to increase the percentage of students able to pass the course and to decrease the drop-out rate.

I thought that I could achieve that goal by: i) encouraging the students to study and practise more Operating Systems; ii) making the students work more during the class; and, iii) avoiding that students make the same mistakes in several practical works.

Many students had already been told by their colleagues that passing Operating Systems was really hard because of the many related and complex concepts. Therefore, some students came to the course 
Figure 3. Graph of the students' opinion regarding the feedback after the practical work during the 2006/2007 course on the left (a), and during the 2007/2008 course on the right (b). Below (c), opinion for the 2007/2008 students regarding the feedback before the practical works

a)

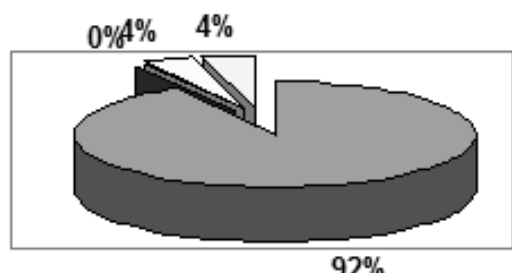

$92 \%$

\begin{tabular}{|l|}
\hline$\square$ Us eful \\
$\square$ Dis like \\
$\square$ Hate \\
$\square$ Blank
\end{tabular}

b)

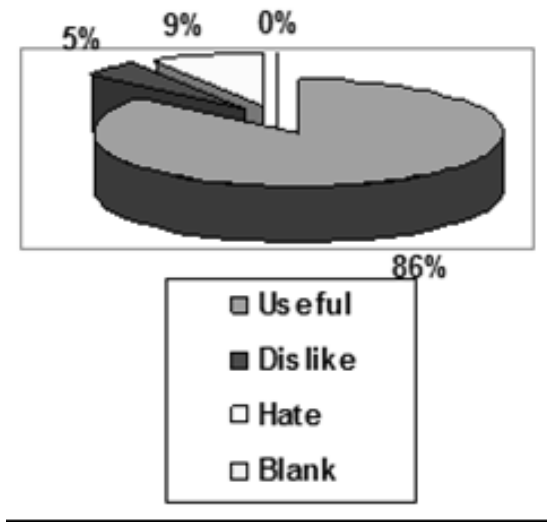

c)

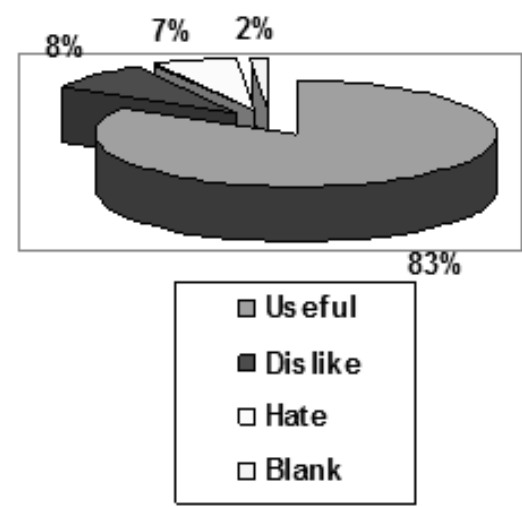

Figure 4. Opinion of the students of the 2006/2007 academic coure, on the left (a); and, the students of the 2007/2008 academic course, on the right (b) about the use of continuous assessment in the university

a)

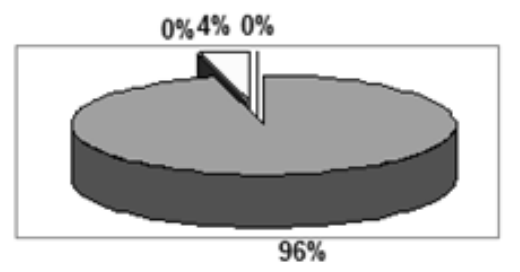

口Like $\square$ Dislike $\square$ Hate $\square$ Blank b)

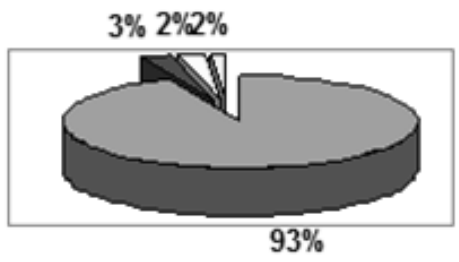

$\square$ Like $\square$ Dis like $\square$ Hate $\square$ Blank convinced that not matter the effort they made, they would not be able to pass Operating Systems.

I tried to actively involve the students in the practical works from the very beginning of the course so that students could realise that if they kept working, they would be able to learn and pass the course, irrespectively of what their older colleagues told to them. 
Figure 5. Opinion of the students regarding if they believe that they are able to take advantage of the lessons in class in the 2006/2007 on the left (a); and, in the $2007 / 2008$ on the right (b)

a)

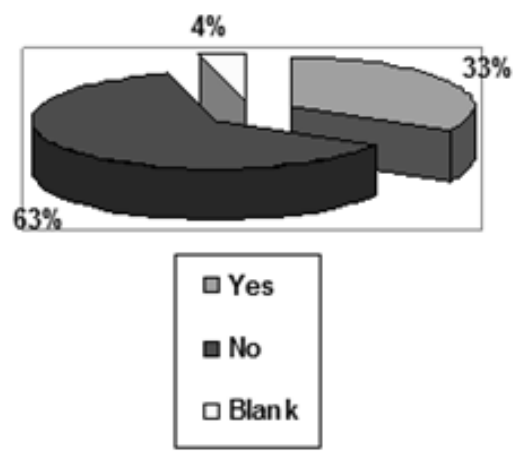

b)

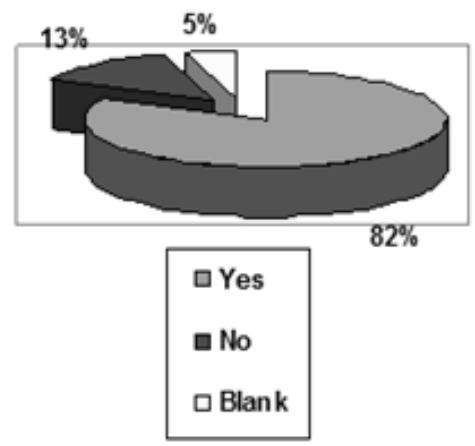

Figure 6. Opinion of the students regarding the future of the course and, how students would like that this type of continuous assessment would keep the same

a)

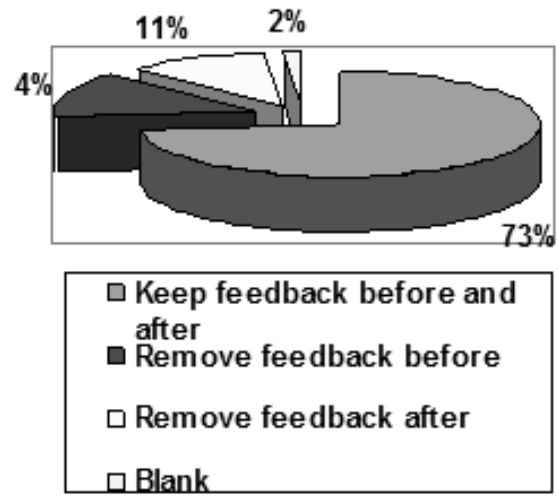

b)

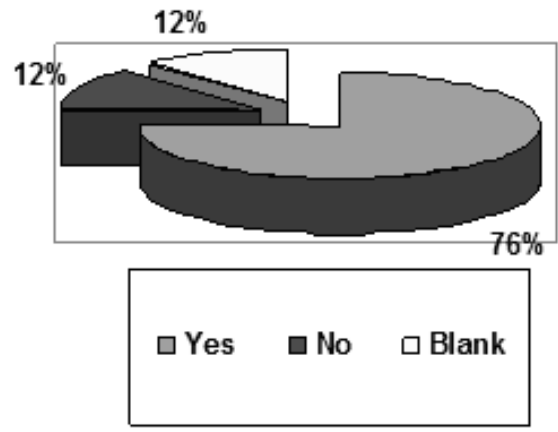

quences of the effort devoted to the course. This is why in the 2006/2007 course I started to provide feedback during the course.

My main concern, at that time, was not having enough time, to review each practical work as I already had to review journal papers and other research and management duties with hard deadlines to meet.

All in all, the planification of an agenda (see Figures 1 and 2) in which to review the work of the students was given the same importance than to the rest of my duties revealed to me that it was not necessarily a very time consuming activity if I focused on several key aspects of each practical work.

Furthermore, from the lecturer perspective I noticed that given that I was keeping track of each pair of students I started to need less time to review their works, because I already knew the main diffi- culties of each pair of students and in which aspects they needed more support.

From the perspective of the students, I also noticed that students felt that their effort in doing each practical work was rewarded with feedback by the lecturer, and they told to me that it was encouraging to keep working for the next practical work knowing that they were on the right track.

Nevertheless, some students were not so happy with the lecturer giving so much attention to the works already presented, and they were more concerned about the still pending works. Therefore, they complaint that the time devoted in class for feedback of their previous works prevents them to have more information about the next works.

I thought about how to solve that, and my next challenge was to provide feedback before and after each practical work, so that students would still have 
feedback about their previous works, while also being guided for the next practical exercises.

That was a real hard challenge because during the 2007/2008 year the number of students increased up to 164, and I was unsure that I could attend all the doubts in class and after class to assess all the work.

However, I was convinced after the good results of the first year that I should try to keep motivating the students with continuous assessment. The main change that I needed to do to cope with all my duties and the high number of students was to restrict more the key aspects to comment on each practical work.

Again, I noticed that as I started to have more information about each pair of students, it was easier to provide feedback because I already knew the more important points to review in each case.

Students had a very positive reaction to this change as they were supported in the aspects in which they needed more help, and they observed that they were more efficient in their work. Some of the students even claimed that they were able to complete some of the practical works during the class, while traditionally the number of hours they had to devote to the course was four times bigger as they were lost in some programming problem they did not know how to solve.

Another important change was to decrease the number of practical works to three. This was positive both from the students and the lecturer perspective. Students were not overwhelmed with too much work and they could follow the lessons better; and, I noticed that I had more time for the rest of my duties as I did not have to review all the weeks some practical work.

\section{Conclusion}

Feedback before and after each practical work is positive both from the lecturer and student perspectives.

Lecturers can see how their students are more motivated, work more during the lessons and the students' scores are higher while the drop-out rate decreases.

Students can understand better what they have to do, avoid making the same mistakes during the course, while feeling that the effort devoted to the course is rewarded with the comments given by the lecturer.

The result of introducing more feedback in the courses have been very positive: while in the 20042005 academic year, $66 \%$ of total number of students passed the course with an average score of 6 (in a 0-10 scale); in the 2005-2006 academic year, $74 \%$ passed the course with an average score of 5,5; in the 2006-2007, in which the continuous assessment with feedback after each exercise was performed, $83 \%$ passed the course with an average of 7,5 and only the 4,5\% students that dropped out the course failed it; and, in the 2007-2008, in which the continuous assessment with feedback before and after each exercise was performed, $100 \%$ of the students passed the course with an average of 7,5.

The results of a satisfaction questionnaire filled in anonymously and voluntarily by 22 students of the $2006 / 2007$ course indicated that $92 \%$ of the students considered useful the feedback provided, and in the course 2007/2008, 93\% of the 133 students who filled in the survey, claimed that they preferred having feedback before and after each practical work.

Therefore, not only the feedback has been positive for the students' performance with an increase in the percentage of students who pass the course, and the average score in two points, but also the perceived satisfaction of the students has been improved.

However, I would also like to warn that it is only possible to take advantage of these benefits provided that the number of practical works is low (not more than 4 practical works per semester), and that the lecturer can focus the feedback on some key aspects of each practical work (in my opinion, it would be difficult to extrapolate this case to more subjective assessment courses).

For the future, more research into how the procedure can be improved and adapted would be benefi- 
cial to extend the benefits found to other courses as well.

\section{References}

Ausubel, D. P. (1963). The Psychology of meaningful verbal learning. New York: Grune and Stratton.

Benito-Capa, A. \& Cruz-Chust, A. (2005). Nuevas claves para la docencia universitaria: en el espacio europeo de educación superior. Narcea.

Brooks, C., Greer, J., Melis, E., \& Ullrich, C. (2006). Combining ITS and elearning technologies: Opportunities and challenges. Intelligent Tutoring Systems, 4053, 278-287.

Irons, A. (2007). Enhancing Learning through Formative Assessment and Feedback (Key Guides for Effective Teaching in Higher Education). Routledge.

Jensen, E. (1998). Teaching With the Brain in Mind. Association for Supervision y Curriculum Development.
Kolb, D. A. (1984). Experiential Learning. Englewood Cliffs, NJ: Prentice-Hall.

Lilley, M., Barker, T., \& Britton, C. (2005). Automated Feedback for a Computer-Adaptive Test: A Case Study. Paper presented at the $9^{\text {th }}$ International Computer Assisted Assessment Conference, Loughborough, U.K.

Marchesi, A. (2004). Qué será de nosotros, los malos alumnos. Alizanza Editorial.

Quality Assurance Agency. (2000). Code of practice for assurance of academic quality and standards in higher education. Technical report, Quality Assurance Agency for Higher Education.

Race, P. \& Pickford, R. (2010). Engaging with Feedback in Higher Education: The Complete Guide. Routledge.

Westberg, J. \& Jason, H. (2001). Fostering Reflection and Providing Feedback: Helping Others Learn from Experiences. Springer Publishing Company.

Zimmerman, B. J. (1990). Self-Regulated Learning and Academic Achievement: An Overview. Educational Psychologist, 25, 3-17.

Manuscrito recibido: $13 / 12 / 2010$ Revisión recibida: 02/02/2011 Manuscrito aceptado: 07/02/2011 